\title{
How Can We Reduce Attrition in General Surgery Residents?
}

Daniel M. Avery*, Charles E. Geno, J oseph C. Wallace, J ohn Burkhardt, Gregg Bell, Andrew G. Harrell, Garrett Taylor, and Catherine Skinner Department of Obstetrics and Gynecology, College of Community Health Sciences at The University of Alabama in Tuscaloosa

*Corresponding author: Avery DM, Department of Obstetrics and Gynecology, College of Community Health Sciences, University of Alabama, Box 870374, Tuscaloosa, AL 35487-0326, USA. Email: davery@ua.edu

Received: December 21, 2017; Accepted: J anuary 25, 2018; Published: February 12, 2018

\section{Introduction}

General surgery residencies have the highest rate of attrition of all training programs [1-4]. Lifestyle issues remain the number one reason residents quit general surgery residencies [5]. One out of every 6 general surgery residents withdraw from training $[1,6]$. The national attrition rate for general surgery is $20 \%$ which is 4 to 5 times higher than surgical subspecialties and 2 to 3 times higher than internal medicine $[1,3,7]$. Almost half of surgery residents consider dropping out of residency [8]. Once a resident decides that surgery will not provide a quality lifestyle, quitting the residency is inevitable [9]. Attrition usually occurs early in training, typically after the first two years [10] but can also occur during the research year [11]. The number of medical students interested in surgery has been decreasing over the last 3 decades [12].

The 80 hour work week rule and elimination of the pyramid system were thought to have helped reduce attrition but neither have had any effect $[11,13]$. Limitation of work hours probably should have helped the attractiveness of the specialty but has not [13]. Of interest, almost half of medical students do not plan to practice medicine full time [14]. Most surgery programs have been affected by attrition and onethird of programs have lost more than one resident [10]. The attrition rates [5] are significantly higher in females compared to males due to discrimination against women, lack of female role models, negative attitudes against women in surgery and sexual harassment [5]. There are 249 general surgery residencies producing 1020 graduates. Some $79 \%$ pursue subspecialty training leaving approximately 200 general surgeons to go into practice nationally [15].

Research should be directed in determining the cause of attrition and trying to reduce it [5]. Many suggestions have been made that may reduce attrition in general surgery residents. Sometimes attrition is predictable when a resident is obviously struggling because of technical performance, distractions, personal issues or career uncertainty [13]. When a resident leaves, it has a significant effect on the entire residency. The remaining house-staff must take up the slack in night, weekend and holiday call, rounds, surgery cases, clinic duties, presentations and Grand Rounds [13]. Loss of a resident adds to the stress, frustration and career uncertainty of the remaining residents [13]. It may start the cascade of other residents leaving [13]. Conversely, attrition often does result in harmony in the training program and in the departing resident [13].

\section{Program directors and faculty must be proactive about retaining residents}

Residency Program Directors (PD) and Surgery Faculty must be vigilant and proactive about retention of general surgery residents because many surgery residents contemplate leaving residency [16]. More female residents leave residency than male and they usually leave early [16]. Faculty need to be mindful of what is going with the residents so that intervention is possible if problems are identified early enough [5]. When a resident is discouraged to the point of leaving residency, it is hard to appreciate the value of continuing surgery training and most quit [5]. The most common reason residents quit general surgery is uncontrollable lifestyle [5]. Almost half of female residents leave after the first year [5]. Women also leave for other reasons like lack of role models and mentors, sexual discrimination and harassment and feeling unwanted in the surgical suite [5]. Early identification and intervention are critical [5].

\section{Residents need guidance during the training program}

Residents need guidance during the residency with feedback, encouragement, evaluations, and milestones [17]. Residents are concerned about their performance [18]. They need to know what the residency program expects of them from the start $[5,17]$. Today, house-staff have portfolios and know the milestones commensurate with their level of training [9]. They should receive progress reports, evaluations and feedback on their performance in addition to the annual end of the year in-service examinations [17]. Learners must perform certain numbers of each procedures to be competent at performing that procedure. Excellent work must be encouraged [17]. Residency programs must follow work hour guidelines and restrictions and the workload must be commensurate with the work hours. Programs must keep research year residents in touch with the residency and the other residents because that year is a common time to quit a surgery residency. Residents in the research year feel 
detached from the rest of the program. Some clinical responsibilities, journal club, grand rounds, morbidity and mortality conference, and even residency social functions may keep research year residents in touch and reduce attrition that accompanies this year.

\section{Better education of medical students about surgery residencies}

Educating medical students about what general surgery residency and practice are like is crucial [6]. Most medical students decide on a residency and career during the third year clerkships [19]. Students are most influenced during the clerkships [19]. A major concern is the misconception of what a general surgery is like [10]. No medical student should matriculate into a surgery residency who is not willing to commit to the work, time and demands, both during residency and for a career beyond [20]. Attrition early in residency suggests that the actual residency training was different from medical school expectations of the new intern [11]. Program Directors (PD) and surgery faculty need to be more involved with medical students who express an interest in general surgery as a career [21].

It is important for students pursuing a general surgery residency to understand the demands and expectations of a surgery resident [20]. Limited exposure to surgery poorly prepares medical students for the actual life of a resident and then residents become discouraged and are at risk for quitting [22]. Medical students evaluating the surgery clerkship requested more case studies, more surgical experience, elective time, more postoperative management, more subspecialty surgery exposure and more technical skills training [23]. Longitudinal integrated experiences in general surgery may better prepare medical students for general surgery [23]. The only real exposure to general surgery is often surgery residents and less interaction with private practice general surgeons [12]. Medical students need exposure to private practice general surgeons to determine if they like general surgery [8]. Positive experiences increase the likelihood of pursuing general surgery such as the number of cases scrubbed on, resident interaction, faculty interaction and the number of cases observed [24]. Surgery residents can be great mentors [25].

\section{Better preparation of medical students for residency training}

An acting internship, or "AI," allows a medical student to gain experience as a surgery intern in an actual general surgery residency. The "AI" functions exactly like an intern for the duration of the rotation, scrubbing in on cases, closing the operative incision, writing postoperative orders, and/or entering orders electronically on the electronic medical record. They also oversee consultations in the emergency department, on the hospital floors, in the intensive care units and take "first call" at night. This experience better enables the student to determine if the life of a surgery resident is right for them. The extra time spent in the "AI" helps students understand what would be expected of them from a medical perspective while also preparing them psychologically for surgical residency. It also serves as a proxy "audition" for that residency program, since medical students usually do "AIs" at hospitals with a general surgery residency into which they could matriculate.

Better Pre-matriculation screening and selection of medical students for surgery residency

Selecting residents is an important part of the challenge of running a surgery residency [20]. While medical student applicants must be academically acceptable, non-academic factors may be more important [26]. Elimination of applicants at high risk for attrition from the applicant pool before the match is recommended [26]. When residents quit, improving resident replacement with qualified physicians is imperative [26]. Most students (89\%) select surgery as a career "because of the nature of surgical practice" [27]. Most residents (76\%) quit because of lifestyle issues [27]. Grit is a character trait defined as passion and perseverance for long term goals and may be a marker for residency attrition [27].

\section{Identification of residents at risk for attrition}

Program directors must be able to target residents at risk for attrition and in trouble so that intervention is possible [26-28]. Many risk factors for attrition have been identified including older age, postgraduate year, academic training program versus a community residency, lack of a mentor, the presence of fellowships, many chief residents, and lack of Alpha Omega Alpha (AOA) status [9,21-23]. Non-academic factors may be more important in predicting attrition [26]. We also need to identify potential dropouts before the match to maintain quality and eliminate those at high risk from the applicant pool [26]. Surgery residents with less confidence are more likely to pursue postgraduate fellowships for additional training [25]. Attrition early in residency usually suggests that the residency was different than expected [29]. "AIs" allow training programs to determine the abilities of medical students and if he or she would be an acceptable candidate to rank in the match. How a resident handles stress has also been suggested to be related to success in life including completing a surgery residency [10].

\section{Positive role models especially for women and minority underrepresented residents}

There is a need to portray general surgeon's lives to residents and students as a sense of purpose in what they do, a commitment to high quality care, and professional satisfaction [6]. Students respond well to positive resident and attending role models [30]. Successful female role models are important for female surgery residents who need someone to emulate. Most private surgeons despite job satisfaction would agree that their work limited personal and family time. Only a small minority of general surgeons would not recommend surgery as a career specialty [12]. There are very few underrepresented role models for minorities and this probably translates into minimal interest in general surgery from underrepresented minorities [20].

\section{Faculty mentors including female mentors}

Mentoring during surgery residencies can help reduce attrition by intervening with residents contemplating withdrawal from the residency [20]. Residents in general surgery can be excellent educators and mentors and can influence medical students pursuing a general surgery career [25]. Gender specific faculty mentors are critical for female medical students interested in surgery [29]. There are very few female general surgery mentors primarily because of the lack of female general surgeons. Female medical students have depended on both male and female mentors because of so few female surgery mentors. While male mentors are important historically, female mentors have the advantage of experience with pregnancy, breastfeeding, pumping and child-raising that males would not have. More importantly if the female medical students can learn from a female mentor that 
being a female surgeon can fit into a family oriented lifestyle they are more likely to pursue surgery. Structured mentoring has been shown to reduce burnout [29]. Factors associated with quitting include absence of a faculty mentor [8]. Perceived satisfaction of the specialty by mentors is important [6]. Female surgeons are more likely to recommend surgery to female students than male surgeons [12].

\section{Accommodations specific for female residents}

Pregnancy, bearing children, breastfeeding and raising a family is challenging; balancing motherhood and a professional life as a general surgeon is even more difficult [16]. Female residents in all specialties have children during residency training. Formal policies addressing pregnancy, maternity leave, breastfeeding and pumping, and parenting are necessary $[18,26]$. Residency programs need contingency plans when female residents cannot work and/or perform clinical duties such as complications of pregnancy and sick infants such as preterm deliveries $[18,26]$. Plans for not overburdening other residents because of another resident's pregnancy are important [26]. Having such policies and plans will provide for greater happiness among everyone concerned [26].

The most common benefit for female surgery residents and practicing general surgeons is formal maternity leave [18]. Maternity leave is essential for female physicians in any specialty and at any level of training. While many female physicians have had children during medical school and residency, only $25 \%$ of women have their first children during surgery residencies [31]. Women must make more sacrifices during residences such as marriage and childbearing [18]. Childcare is essential for female surgery residents who have children. On-site daycare is preferable but uncommon [6,12]. Most female surgeons who have children during residency complete residency on time, pass boards and see as many patients during residency [32]. Accommodations and flexibility for women are imperative because a third of surgery residents are female. The work environment must be made amenable to women [33]. Female medical students, residents, faculty and leaders must be actively pursued [33].

\section{Improving confidence for residents}

Progression of surgery residency training depends on the development of confidence [18]. Normally, confidence increases with progression of residency training culminating with the ability of a chief or senior resident to function as a junior attending and ultimately to practice general surgery independently. [18]. Residency programs may improve factors that relate to low confidence [18]. Learning experiences improve surgical confidence [34]. Confidence is better in community programs, programs with fewer chief residents, and programs without fellowships [18]. Senior medical students in surgery improve their confidence during residency $[12,18]$. Decreased confidence is associated with the need to pursue further training in a fellowship [18]. Fellowship training narrows their surgical focus after training and reduces their spectrum of general surgery. Female surgery residents worry about their performance more than males and often this results in quitting residency [18].

Female surgery residents have been shown to struggle more with confidence than their male counterparts, often leading them to quit [12]. General surgery residents who were female, single or did not have children had decreased confidence in their surgical ability compared to their peers [12]. Women were twice as likely to worry about their surgical competence after residency, prompting many to pursue fellowships [12].Residency programs can take steps toward promoting resident confidence levels by offering more learning experiences, including clinical simulation [12]. Practical learning experiences increase confidence [18].

\section{Keep residents connected during the research year}

During the research year, residents feel disconnected from the training program, fellow residents, faculty advisors and mentors. This probably accounts for the fact that the research year is a common time to quit the residency $[6,10]$. Residents need to remain connected during their research years [11]. Periodic operating, journal club, social events, grand rounds, morbidity and mortality conferences, regular meetings with mentors, and didactic sessions may help keep residents better connected during their research year.

\section{Bullying prevention}

Bullying is the intimidating, overbearing behavior characteristic of "the surgical personality" which interferes with communication, quality patient care, patient safety, and teamwork, seen characteristically in the operating room and postoperative care [34]. Bullying has also been proposed as a systems level issue that contributes to "the surgical personality" and attrition [34]. Overbearing surgeons are ill-mannered and ill-tempered. Bullying contributes to attrition of surgery residents [34]. As more women matriculate into general surgery, the male dominated environment should change as most female surgeons do not have the "surgical personality [34]. Female surgery residents are more concerned with the feelings of others than male residents as a rule [34]. The duty hour change has helped make general surgery more attractive [34]. Residents who are rested and not perpetually exhausted work better under stress [34].

\section{Burnout reduction}

Burnout is a serious concern for general surgery residents of either gender. Some $69 \%$ of surgery residents meet the criteria for burnout, and female residents are more likely to be affected by and report burnout than their peers $[17,35]$. The long work hours required of a general residency are almost always cited as a primary reason for burnout. Almost half of general surgery residents consider quitting their surgery residency and an equal number would not select general surgery for a career again [35]. It had been hoped the work hour restrictions would have reduced burnout but that has not been the case [29]. A study by the American College of Surgeons suggests that private practice surgeons are more likely to experience burnout and lower career satisfaction than surgeons practicing in academic settings [36].

Improved support systems, increased availability of mentors, crisis intervention, wellness programs, and counseling may help reduce burnout $[5,16]$. Brooks and Bosk found that "duty regulation hours had made the field of surgery more attractive to women and men seeking a more balanced life" [36]. Providing students with more information about which environments are more likely to create burnout could be a useful intervention in burnout reduction. A structured mentoring program has been associated with lower levels of burnout [29]. Mentoring programs may be a first line defense against burnout [29]. 


\section{Reduce discrimination against females}

Many female medical students believe that surgery discriminates against women and many feel out of place in the operating suite [5]. Much of this comes from lack of female role models and lack of a life outside the hospital [5]. This can be improved with more female general surgeons who are role models and mentors. It is important to change the professional environment for women [33]. As more women matriculate into general surgery, the male dominated environment should change [34].

\section{Psychological assessment before residency}

Ninety-nine percent of medical students rank general surgery as the first or second most stressful medical specialty [37]. An older 1984 paper suggests that some medical students may tolerate stress better than others and may make better surgery residents [38]. The World of Work Inventory Online (WOWI Online] multidisciplinary assessment has been used to determine a stable profile of surgeons and suitability for the surgical profession [9]. This has been shown to be a consistent, reproducible personality assessment which could be useful in predicting success in a residency program and practice of surgery [9]. The question remains if it could be useful to predict success of matriculates to surgery residencies [9].

Many students interested in surgery have been described as "aggressive, self-confident, competitive, thick-skinned, and authoritarian" [20]. They have less anxiety and are resistant to stress [37]. Personality may determine specialty choice-the desire to fix things, correct problems, and have immediate results has been thought to be desirable for surgery [37]. As discussed above, Grit may be a marker for attrition as low scores have been associated with residents contemplating quitting residency [39].

\section{Social support, intervention and counseling programs}

Strong systems of social support increase the odds that a resident will complete their training [35]. Support from family, spouses, partners, and peers in the program all contribute to resident success by helping them to cope with the stresses of the residency [35] Access to mentoring and support by administration also helps to reduce attrition [14]. Crisis intervention programs teach residents how to deal with fatigue, stress, work hours, disasters, bad outcomes, complications, patient deaths, and litigation [5]. Residents are often overwhelmed because of the demands of surgery residencies compared to other specialties. The ability to deal with acute stresses may reduce attrition.

Counseling is important for residents with personal difficulties, marital problems, and financial challenges and can help reduce the stresses of residency [5]. Mentoring and guiding residents through the trials and tribulations of residency are important [5]. Fear of dismissal is a common threat for surgery residents and usually stems from lack of feedback on progress. Encouragement is important for learners of all ages. All learners need feedback about their progress including surgery residents where technical skill is a significant part of what they do. While surgery residencies are teaching resident's techniques to deal with fatigue, OB/GYN residents who also do a lot of work at night learn to sleep in a corner anytime they can. They also try to get "prophylactic sleep" early in the evening on night call if nothing is going on.

\section{Conclusion}

General surgery residencies have the highest rate of attrition of all residencies [1-4]. Lifestyle is the top reason surgery residents quit [5]. One out of every 6 residents quits $[1,6]$. Nearly half of residents consider quitting residency [8]. The number of medical students interested in a general surgery career has been dropping over the past 3 decades [12]. Attrition is higher in females than males [5]. Attrition hurts the residency program because remaining residents have to pick up the extra work [13].

Reducing attrition is critical to maintaining a sufficient number of general and rural surgeons in this country. The national standard of attrition is $20 \%[1,3,7]$. Since most residents quit general surgery because of lifestyle issues, it seems prudent to consider improving the lifestyle issues. Female general surgeons are the opportunity to supply a sufficient number. While many ideas to reduce attrition were discussed in this paper, the key is being proactive and vigilant to identify problems early before quitting is inevitable. Making general surgery attractive to medical students is also important. Mentoring programs may help reduce burnout [13].

\section{References}

1. Avery DM, Wallace JC, Avery DM, Harrell AG, Burkhardt J, Henderson C, et al. Attrition of General Surgery Residents during Training. Jacobs Journal of Surgery. 2017; 4: 031.

2. National Residency Match Program. Residency Match Results by NRMP Year for UAB SOM Graduates by Campus. 2015.

3. Fischer JE: The Impending Disappearance of the General Surgeon. JAMA 2007; 298: 2191-2193.

4. Newton DA, Grayson MA: Trends in Career Choice by US Medical Schoo Graduates. JAMA. 2003; 290: 1179-1182.

5. Bachert A: Residents Continue to Quit General Surgery. Journal of Medicine. 2017.

6. Dodson TF, Webb ALB: Why Do Residents Leave General Surgery? The Hidden Problem in Today's Programs. Curr Surg. 2005; 62: 128-131.

7. Cogbill TH, Cofer JB, Jarman BT. Contemporary Issues in Rural Surgery. Curr Prob Surg. 2012; 49: 263-318.

8. Barone JE. More Than Half of General Surgery Residents Think About Quitting. Healthy Living.

9. Foster KN, Neidert GP, Brubaker-Rimmer R, Artalejo D, Caruso DM. A Psychological Profile of Surgeons and Surgical Residents. J Surg Educ. 2010; 67: 359-370

10. Morris JB, Leibrandt TJ, Rhodes RS. Voluntary Changes in Surgery Career Paths: A Survey of the Program Directors in Surgery. J Am Coll Surg. 2003 196: 611-616.

11. Yeo H, Bucholz E, Sosa JA, Curry L, Lewis FR, Jones AT, et al. A Nationa Study of Attrition in General Surgery Training-Which Residents Leave and Where Do They Go?. Ann Surg. 2010; 252: 529-536.

12. Schroen AT, Brownstein MR, Sheldon GF. Comparison of Private Versus Academic Practice for General Surgeons: A Guide for Medical Students and Residents. J Am CollSurg. 2003; 197: 1000-1011.

13. Longo WE. Attrition: Our Biggest Continuing Challenge. Am J Surg. 2007; 194: 567-575.

14. Leibrandt TJ, Pezzi CM, Fassler SA, Reilly EF, Morris JB. Has the 80 Hour Work Week Had an Impact on Voluntary Attrition in General Surgery Residency Programs?. J Am CollSurg. 2006; 202: 340-344.

15. Whellen TV. Training Surgeons for Tomorrow. AAMC, 2006. 
16. Twachtman Gregory. Many Surgical Residents Consider Quitting During Training. ACS Surgery News. 2014; 2014.

17. Mc Greevy JM. Maximizing Postgraduate Surgical Education in the Future ACS Bulletin. 2012.

18. Bucholz EM, Sue GR, Yeo H, Roman SA, Bell RH, Sosa JA. Our Trainees' Confidence. Arch Surg. 2011; 146: 907-914.

19. Al-Heeti KMN, Nassar AK, DeCorby K, Winch J, Reid S. The Effect of General Surgery Clerkship Rotation on the Attitude of Medical Students Towards General Surgery as a Future Career. J Surg. 2012; 69: 544-549.

20. Evans S, Sarani B. The Modern Medical School Graduate and General Surgery Training. Arch Surg. 2002; 137: 274-277.

21. Avery DM, Wallace JC, Skinner CA, Burkhardt J, Bell G, Geno CE, et al. How Can We Retain More Female Residents in General Surgery Residencies? A Study of 789 Medical School Graduates from 3 Campuses Who Matched into General Surgery Residencies over 40 Years: 1974 to 2015. Submitted to Jacobs Journal of Surgery. 2017; 2: 1720.

22. Avery DM, Wallace JC, Burkhardt J, Bell JG, Geno CE, Harrell AG, et al. Why Do Residents Quit General Surgery Residencies? A Study of 789 Graduates from Three Campuses Who Matched into General Surgery over 40 Years: 1974 to 2015. ClinSurg. 2017; 2: 1720.

23. Taylor G, Wallace JC, Harrell AG, Burkhardt J, Avery DM, Geno CE, et al How Can We Attract More Medical Students to General Surgery Residencies? A Review of Medical Student Evaluations of a General Surgery Clerkship for 10 Years: 2005 to 2015. ClinSurg. 2017; 2: 1722.

24. O'Herrin J, Lewis B, Rikkers LR, Chen H. Why Do Students Choose Careers in Surgery?. J Surg Res. 2004; 119: 124-129.

25. Musunuru S, Lewis B, Rikkers LR, Chen H. Effective Surgical Residents Strongly Influence Medical Students to Pursue Surgical Careers. J Am Coll Surg. 2007; 204: 164-167.

26. Merchant S, Hameed M, Melck A. Pregnancy Among Residents Enrolled in General Surgery (PREGS): A Survey of Residents in a Single Canadian Training Program. Can J Surg. 2011; 54: 375-380.
27. Burkhart RA, Tholey RM, Guinto D, Yeo CJ, Chojnacki KA. Grit: A Marker for Residents at Risk for Attrition?. Surgery. 2014; 155: 1014-1022.

28. Elmore LC, Jeffe DB, Jin L, Awad MM, Turnbull IR. National Survey of Burnout among US General Surgery Residents. J Am Coll Surg. 2016; 223: 440-451.

29. Phillips D. 'Alarming' Burnout Rate in General Surgery Residents. Medscape. 2016.

30. Berman L, Rosenthal MS, Curry LA, Evans LV, Gusberg RJ. Attracting Surgical Clerks to Surgical Careers: Role Models, Mentoring and Engagement in the Operating Room. J Am Coll Surg. 2008; 207: 793-800.

31. Martin N. Women Surgeons and the Challenges of Having It All. News. 2015.

32. Ronnie c. Pregnancy Doesn't Drive Women Doctors out of Surgical Training, Health News. 2014

33. Freischlag JA. Women Surgeons-Still in a Male-Dominated World. J Biol Med. 2008; 81: 203-204.

34. Brooks JV, Bosk CL. Bullying is a Systems Problem. Social Science \& Medicine. 2012; 77: 11-12.

35. Contessa J, Kyriakides T. Surgical Resident Attrition and the Menninger Morale Curve. Surgical Science. 2011; 2: 397-401.

36. Sullivan MC, Yeo H, Roman SA, Ciarleglio MM, Cong X, Bell RH, et al. Surgical Residency and Attrition: Defining the Individual and Programmatic Factors Predictive of Trainee Losses. J Am Coll Surg. 2013; 216: 461-471.

37. Barshes NR, Vavra AK, Miller A, Brunicardi FC, Goss JA, Sweeney JF. General Surgery as a Career: A Contemporary Review of Factors Central to Medical Student Specialty Choice. J Am Coll Surg. 2005; 199: 792-799.

38. Linn BS, Zeppa R. Does Surgery Attract Students Who Are More Resistant to Stress. Ann Surg. 1984; 200: 638-643.

39. Burkhart RA, Tholey RM, Guinto D, Yeo CJ, Chojnacki KA. Grit: A Marker for Residents at Risk for Attrition? Surgery. 2014; 155: 1014-1022.
Austin J Surg - Volume 5 Issue 3 - 2018

ISSN : 2381-9030 | www.austinpublishing group.com

Avery et al. (C) All rights are reserved
Citation: Avery DM, Geno CE, Wallace JC, Burkhardt J, Bell G, Harrell AG, et al. How Can We Reduce Attrition in General Surgery Residents?. Austin J Surg. 2018; 5(3): 1129 